This document is the Accepted Manuscript version of a Published Work that appeared in final form in:

Forouli A., Doukas H., Nikas A., Sampedro J., Van de Ven D.-J. 2019. Identifying optimal technological portfolios for European power generation towards climate change mitigation: A robust portfolio analysis approach. Utilities Policy. 57. 33-42. DOI (10.1016/j.jup.2019.01.006).

(C) 2019 Elsevier Ltd. All rights reserved.

This manuscript version is made available under the CC-BY-NC-ND 3.0 license

http://creativecommons.org/licenses/by-nc-nd/3.0/

\title{
Identifying optimal technological portfolios for European power generation towards climate change mitigation: a robust portfolio analysis approach
}

\begin{abstract}
In this paper, an integrative approach is proposed to link integrated assessment modelling results with a novel portfolio analysis framework for robust modelling. The approach is applied for identifying optimal technological portfolios for power generation in the EU towards climate change mitigation, in a timescale until 2050. The technologies considered include photovoltaics, concentrated solar power, wind, nuclear, biomass and carbon capture and storage. The proposed approach links data from the Global Change Assessment Model (GCAM), namely subsidy curves for emissions reduction and energy security for the six power generation technologies until 2050, with other decision support methods, in the aim of managing the inherent uncertainty and assessing the robustness of the optimal portfolios. The modelling results are then integrated in a bi-objective evaluation model for portfolio analysis. The model treats uncertainty stochastically, using a Monte Carlo simulation algorithm and the Iterative Trichotomic Approach, and defines specific portfolios of electricity generation technologies as the most robust. The results are presented and discussed, mainly in terms of highlighting the robustness of the Pareto optimal solutions, which is essential for policymakers to be more confident when selecting technology portfolios that feature a high degree of uncertainty, regarding their vulnerability to different future developments. By aggregating the results to one robust technological portfolio, the proposed approach features the potential to subsequently be linked to a deterministic model.
\end{abstract}

Keywords: decision support, power generation, technology R\&D, portfolio analysis, uncertainty, robustness.

[Type here] 
This document is the Accepted Manuscript version of a Published Work that appeared in final form in:

Forouli A., Doukas H., Nikas A., Sampedro J., Van de Ven D.-J. 2019. Identifying optimal technological portfolios for European power generation towards climate change mitigation: A robust portfolio analysis approach. Utilities Policy. 57. 33-42. DOI (10.1016/j.jup.2019.01.006).

(C) 2019 Elsevier Ltd. All rights reserved.

This manuscript version is made available under the CC-BY-NC-ND 3.0 license

http://creativecommons.org/licenses/by-nc-nd/3.0/

\section{Introduction}

The EU has set a long-term goal of reducing greenhouse gas (GHG) emissions by $80-95 \%$, when compared to 1990 levels, by 2050. Towards achieving this target, the Commission has published an Energy Roadmap for 2050 to explore cost-efficient ways to make the European economy more climate-friendly and less energy-consuming, while also increasing competitiveness and security of supply (EC, 2016a.). It is clear that all main sectors responsible for Europe's GHG emissions - power generation, industry, transport, buildings, construction and agriculture- need to contribute to this low-carbon transition according to their technological and economic potential. In 2015, one quarter of global GHG emissions was caused by fossil fuel combustion in power plants (IPCC, 2014), while in Europe emissions of fuel combustion by energy industries amounted to $28.2 \%$ of total GHG emissions (Eurostat, 2017). Decarbonising electricity generation is therefore crucial to the efforts towards climate change mitigation (Arvesen et al., 2018) and has the potential to almost totally eliminate $\mathrm{CO}_{2}$ emissions by 2050 , by exploiting renewable energy sources (e.g. solar, wind, biomass, etc.), using other low-emission alternatives like nuclear power plants, or maturing and diffusing carbon capture and storage (CCS) technologies in fossil fuel power stations (EC, 2016b).

On the basis of the above, the need to secure support for coordinated environmental, climate, and energy planning emerges. Particularly, the process of designing technological mixes for electricity generation takes on special significance in the context of energy and environmental planning. In this process, cost-related parameters are first examined; however, other characteristics must also be taken into consideration, including the level of dependence on imported resources; the corresponding energy security and efficiency of the territory; and the social and environmental impact that the use of the available technologies might entail (Valentine, 2011). Thus, energy planning, perceived as a problem of investment selection (Awerbuch, 2004), facilitates the long-term design of the electricity generation mix that best reconciles security of supply, sustainability (economic, social and environmental) and competitiveness (Hickey et al., 2010). What is also important is the diverse nature and uncertain potential of energy technologies that currently are or may later be available to mitigate GHG emissions (Pugh et al., 2011). The long service life of power generation assets and the high level of uncertainty, both stemming from the horizon subject to analysis, strongly impact the different variables of the selection problem, which are a synthesis of technological, economic, regulatory and environmental variables (deLlano-Paz et al., 2017). This further poses a challenge to policymakers trying to invest funds in an optimal electricity generation portfolio (Pugh et al., 2011).

Typically, integrated assessment modelling can prove very valuable to meeting the challenges of sustainability (Jakeman and Letcher, 2003) and is widely used to explore potential strategies for climate change mitigation and energy planning (Krey, 2014). Integrated assessment models 
This document is the Accepted Manuscript version of a Published Work that appeared in final form in:

Forouli A., Doukas H., Nikas A., Sampedro J., Van de Ven D.-J. 2019. Identifying optimal technological portfolios for European power generation towards climate change mitigation: A robust portfolio analysis approach. Utilities Policy. 57. 33-42. DOI (10.1016/j.jup.2019.01.006).

(C) 2019 Elsevier Ltd. All rights reserved.

This manuscript version is made available under the CC-BY-NC-ND 3.0 license http://creativecommons.org/licenses/by-nc-nd/3.0/

(IAMs) give fruitful insights in the tradeoffs and synergies among policy goals; support the identification of important cross-sector interactions; and to some extent consider uncertainty, in factors such as population and economic growth, technology development, human behavior, and climate change (Shi et al., 2017). As a result, key reports targeted to policymakers and the public rely heavily on scenarios produced by IAMs (Arvesen et al., 2018; IPCC, 2014). Despite academic researchers having extensively worked on and employed IAM-based approaches for the purposes of investigating future energy, land use, and emission pathways at global to continental scales (Vuuren et al., 2011), it is important to note that these formalised modelling frameworks face considerable difficulties in giving appropriate responses to short-term patterns of the power sector (Pietzcker et al., 2017). Furthermore, IAMs typically treat uncertainty deterministically, i.e. by means of scenarios (Nikas et al., 2018); Jakeman and Letcher (2003) recognise the need for improved techniques of uncertainty and sensitivity analysis as a central challenge in the use of IAMs. Last but not least, climate-economy modelling by means of IAMs typically excludes policymakers and other stakeholder groups or, limits their participation to the extent of partly formulating the assumptions, by which modelling simulations are driven (van Vliet et al., 2010). Other weaknesses associated with IAMs are extensively discussed in (Doukas et al., 2018).

As a valuable tool in the management of such complex environmental and energy problems (Uusitalo et al., 2015), decision support systems have the potential to effectively summarise and bring together various, distinct consequences related to alternative planning options (Doukas, 2013). As the recent literature suggests, a broadly established approach to meeting the challenges associated with the definition of energy plans for a certain territory or region can be found in Modern Portfolio Theory (MPT). Typically, the portfolio approach is based on the solution of problems with one objective function seeking to minimise either the cost or the risk of the portfolio, subject to different constraints, also considering that real electricity generation assets can be defined in terms of cost or return and economic risk, for each alternative technology (deLlano-Paz et al., 2017). The most exhaustive and complete reviews on the application of MPT in energy planning are found in the studies of Delarue et al. (2011) and Jano-Ito and Crawford (2017). On more topics related to the principles of portfolio theory, the reader is referred to the papers of Awerbuch and Berger (2003), Awerbuch and Yang (2007), Elton and Gruber (1997). Furthermore, Lathtinen et al.(2017) and Pérez Odeh et al (2018) give a comprehensive review of portfolio-oriented decision analysis methods in environmental decision making and portfolio applications in electricity markets respectively.

It is noteworthy that, given that problems of this particular domain are subject to numerous objectives and criteria, the existence of a single optimal solution leading to one particular course of action, upon which the decision maker has no influence, is rarely achieved or meaningful. A solution to this challenge lies in the identification of a Pareto set of optimal solutions (Hamilton et al., 2015). Reaching a set of near-optimal solutions provides a much more fruitful input into

[Type here] 
This document is the Accepted Manuscript version of a Published Work that appeared in final form in:

Forouli A., Doukas H., Nikas A., Sampedro J., Van de Ven D.-J. 2019. Identifying optimal technological portfolios for European power generation towards climate change mitigation: A robust portfolio analysis approach. Utilities Policy. 57. 33-42. DOI (10.1016/j.jup.2019.01.006).

(C) 2019 Elsevier Ltd. All rights reserved.

This manuscript version is made available under the CC-BY-NC-ND 3.0 license http://creativecommons.org/licenses/by-nc-nd/3.0/

the decision making process (Lempert et al., 2016), and is easier to explain than any other practical recommendation. Such analysis is crucial as it can provide a measure of confidence in the ability to differentiate between different decisions (Jakeman and Letcher, 2003; Weyant, 2017). Portfolio analysis (PA) is commonly employed in applications with multiple objectives and widely supports stochastic treatment of uncertainty.

In this paper, an integrated approach to linking IAMs with a novel PA approach towards providing more fruitful and robust policy recommendations, is developed and presented. The proposed approach is applied for the identification of optimal electricity generation portfolios in the EU, in the scope of achieving the goal of transforming Europe into a competitive, lowcarbon economy by 2050 .

Initially, the performance of six electricity generation technologies is examined regarding both the achieved GHG emissions reduction and the respective energy security as a result of specific technological subsidisation. The datasets are obtained from the Global Change Assessment Model (GCAM), a partial equilibrium IAM. The initial modelling results are appropriately aggregated to be utilised for PA. Subsequently a technological R\&D portfolio problem for European power generation technologies is modelled and solved with the use of multi-objective programming and stochastic uncertainty treatment. The portfolio selection problem focuses on an EU-27 level approach, and evaluates different power generation options in a timescale until 2050. The portfolios are evaluated based on their performance with regard to their contribution to the reduction of GHG emissions, and the positive consequences they may induce on energy security. To deal with the inherent uncertainty characterising the basic parameters of the model, namely GHG emission reduction and energy security, a Monte Carlo simulation is carried out. Through this approach, the robustness of the obtained optimal energy technology portfolios can be evaluated, by considering that the uncertainty in the model's parameters is of stochastic nature. The robustness of the Pareto optimal solutions is essential for building confidence among policymakers, when selecting technological portfolios that feature a high degree of uncertainty regarding their vulnerability to probable future developments. By aggregating the results to one robust technological portfolio, the proposed approach can potentially be further linked to a deterministic model.

Baker and Solak (2011) have previously used modelling results from the Dynamic Integrated Climate-Economy (DICE) model and MiniCAM (older version of the GCAM model) IAMs in a stochastic optimisation-oriented PA; while Pugh et al. (2011) aggregated different technological scenarios from the GCAM model into one specific scenario and built a Ranked ROI-oriented optimal R\&D electricity generation portfolio. The present study, however, utilises GCAM outputs to evaluate electricity generation technologies by simultaneously considering two optimisation criteria, namely maximisation of GHG reduction and energy 
This document is the Accepted Manuscript version of a Published Work that appeared in final form in:

Forouli A., Doukas H., Nikas A., Sampedro J., Van de Ven D.-J. 2019. Identifying optimal technological portfolios for European power generation towards climate change mitigation: A robust portfolio analysis approach. Utilities Policy. 57. 33-42. DOI (10.1016/j.jup.2019.01.006).

(C) 2019 Elsevier Ltd. All rights reserved.

This manuscript version is made available under the CC-BY-NC-ND 3.0 license http://creativecommons.org/licenses/by-nc-nd/3.0/

security, and deals with stochastic uncertainty instead of discrete scenarios to obtain robust optimal technological portfolios.

The paper is organised as follows: the following section contains a detailed description of the employed models and methods. The third section proposes an integrated approach to creating links between the different models. In the fourth section, the approach is applied in the case study, the results and robustness analysis are presented in detail and discussed. Finally, some conclusions are presented.

\section{Methods and models}

The proposed approach is based on a blend of different models and methodological frameworks. An overview of the models to be linked in the proposed approach is presented in the following figure (Figure 1).

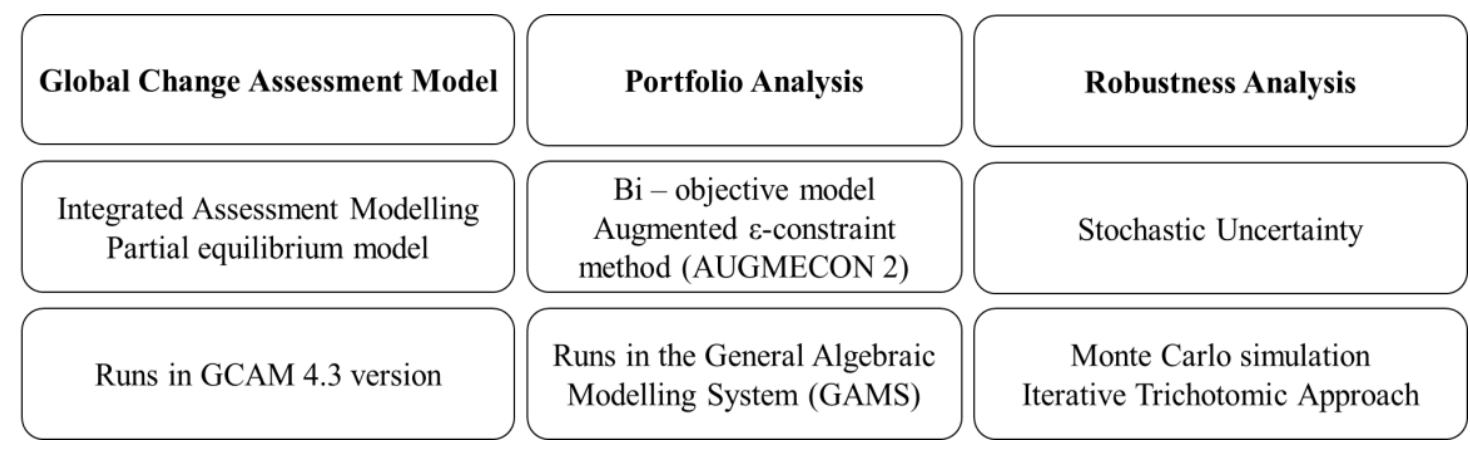

Figure 1: Blend of methods and models to be linked

The different models and methods are concisely described in the following paragraphs.

\section{GCAM}

GCAM is a dynamic-recursive, partial equilibrium model with technology-rich representations of the economy, the energy, water, agricultural, and land use sectors. It was developed by Joint Global Change Research Institute (JGCRI, 2017), a partnership between the Pacific Northwest National Laboratory (PNNL) and the University of Maryland. At a timescale of more than 30 years GCAM and its predecessors (e.g. MiniCAM) have been used in applications investigating future emission scenarios and energy technology pathways (Shi et al., 2017). GCAM is one of the four models chosen to develop the Representative Concentration Pathways (van Vuuren et al., 2011) of the IPCC's $5^{\text {th }}$ Assessment Report (IPCC, 2015) and has participated in almost all of major climate/energy assessment over the last years. It connects socioeconomics, energy, land use and climate modules and it is meant to represent the consequences of climate change mitigation policies, including carbon taxes, carbon trading, regulations and accelerated deployment of energy technology (JGCRI, 2017). Representative

[Type here] 
This document is the Accepted Manuscript version of a Published Work that appeared in final form in:

Forouli A., Doukas H., Nikas A., Sampedro J., Van de Ven D.-J. 2019. Identifying optimal technological portfolios for European power generation towards climate change mitigation: A robust portfolio analysis approach. Utilities Policy. 57. 33-42. DOI (10.1016/j.jup.2019.01.006).

(C) 2019 Elsevier Ltd. All rights reserved.

This manuscript version is made available under the CC-BY-NC-ND 3.0 license http://creativecommons.org/licenses/by-nc-nd/3.0/

applications of the GCAM model include those of Collins et al., 2015; Ebi et al., 2014 and Fisher et al., 2014.

The energy system in GCAM includes primary energy resource production, energy transformation and the use of final energy forms to deliver energy services. The model distinguishes between depletable and renewable resources. Depletable resources include fossil fuels such as oil (both conventional and unconventional), gas and coal, and uranium (for nuclear power); renewable resources include different types of biomass (purpose-grown, municipal waste and residue), wind (on- and off-shore), geothermal energy, hydropower, rooftop areas for solar photovoltaic (PV) equipment and non-rooftop solar, including Concentrated Solar Power (CSP). Regarding the land-use module, the model is divided in 283 agro-ecological zones (Monfreda et al., 2008), which are divided in arable (crops) and non-arable (desert or urban) land categories. GCAM also tracks an important number of GHGs like $\mathrm{CO}_{2}$ (both FFI and land-use) or methane $\left(\mathrm{CH}_{4}\right)$ and the most hazardous air pollutants such as organic and black carbon ( $\mathrm{OC}$ and $\mathrm{BC})$, sulphur dioxide $\left(\mathrm{SO}_{2}\right)$ or nitrogen oxides ( $\left.\mathrm{NOx}\right)$.

For the purposes of this study, the GCAM 4.3 version is used, providing results on a regional level, by examining Europe as a whole instead of individually modelling each European country. There exist other models designed to focus exclusively on the European energy system, such as PRIMES (E3MLab, 2014) and JRC-EU-TIMES (Joint Research Centre, 2013). In comparison to these bottom-up energy system models with disaggregation at the European country level, GCAM is a partial equilibrium model covering the entire European region and the entire economy, featuring both bottom-up and top-down approaches (Urban et al., 2007) as well as representing both endogenous and induced technological progress (Nikas et al., 2018). Last but not least, there have been applications in the literature featuring stochastic uncertainty assessment by means of Monte Carlo analyses at the regional or global level (e.g. Scott et al., 1999), as well as applications integrating the model with PA approaches (e.g. Pugh et al., 2011; Baker and Solak, 2011). All of these reasons constitute the background of our choice to use the GCAM model.

\section{Portfolio Analysis}

Multi-objective optimisation

Unlike single-objective optimisation, where the optimal solution of the problem is usually unique, the optimal solution in multi-objective optimisation is a set of performances across the various objective functions, between which there emerge conflicts. Multi-objective optimisation can be described in mathematical terms as follows (minimisation):

$$
\min y=\left[f_{1}(x), f_{2}(x), \ldots, f_{n}(x)\right] \text { s.to. } x \in \Omega
$$

[Type here] 
This document is the Accepted Manuscript version of a Published Work that appeared in final form in:

Forouli A., Doukas H., Nikas A., Sampedro J., Van de Ven D.-J. 2019. Identifying optimal technological portfolios for European power generation towards climate change mitigation: A robust portfolio analysis approach. Utilities Policy. 57. 33-42. DOI (10.1016/j.jup.2019.01.006).

(c) 2019 Elsevier Ltd. All rights reserved.

This manuscript version is made available under the CC-BY-NC-ND 3.0 license http://creativecommons.org/licenses/by-nc-nd/3.0/

Where $\Omega$ is the feasible solution area and $f_{1}(x), \ldots, f_{n}(x)$ are $n$ objective functions having conflict with each other.

\section{Pareto dominance}

According to Eq. (1), $x^{*}$ dominates another solution $x$ (denoted by $x^{*}>x$ ), if the following two conditions are satisfied:

$$
\begin{aligned}
\forall I \in\{1,2, \ldots, n\}, f_{i}\left(x^{*}\right) & \leq f_{i}(x) \\
\exists k \in\{1,2, \ldots, n\} f k\left(x^{*}\right) & <f k(x)
\end{aligned}
$$

Where $x, x^{*} \in \Omega$

In other words, this definition says that $x^{*}$ is Pareto dominant if there exists no feasible vector $x$ which would decrease some criterion without causing a simultaneous increase in at least one other criterion (assuming minimisation).

It must be noted that, in case of maximisation in the objective functions, only a change in the direction of the inequalities is required.

Pareto optimal and Pareto optimal set

A solution $x^{*}$ is non-dominated and is Pareto optimal if

$$
\nexists x \in \Omega: x>x^{*}
$$

The set of all Pareto optimal solutions is a Pareto optimal set (PS).

\section{Pareto optimal front}

Pareto optimal front $(P F)$ is the set consisting of objective function vectors related to the Pareto optimal set.

$$
P F=\left\{y=\left[f_{1}(x), f_{2}(x), \ldots, f_{n}(x)\right]^{T} \mid x \in P S\right\}
$$

The shape of the Pareto front indicates the nature of the trade-off between the different objective functions.

Therefore, multi-objective optimisation is an approach to finding Pareto optimal solutions and obtaining the Pareto optimal front. A proper multi-objective solution method should lead to the Pareto optimal set and also solutions with appropriate diversity (Chiandussi et al., 2012; Rayat et al., 2017). 
This document is the Accepted Manuscript version of a Published Work that appeared in final form in:

Forouli A., Doukas H., Nikas A., Sampedro J., Van de Ven D.-J. 2019. Identifying optimal technological portfolios for European power generation towards climate change mitigation: A robust portfolio analysis approach. Utilities Policy. 57. 33-42. DOI (10.1016/j.jup.2019.01.006).

(C) 2019 Elsevier Ltd. All rights reserved.

This manuscript version is made available under the CC-BY-NC-ND 3.0 license

http://creativecommons.org/licenses/by-nc-nd/3.0/

The AUGMECON2 method

AUGMECON2 (Mavrotas and Florios, 2013), a new version of the AUGMECON method (Mavrotas, 2009), is a general purpose method, which constitutes an especially suitable method for Multi-Objective Integer Programming (MOIP) problems.

AUCMECON is an improvement of the original $\varepsilon$-constraint method, which is-along with the weighting method - one of the two most popular methods for generating representations of the Pareto front. As described in Mavrotas, 2009, the $\varepsilon$-constraint method has certain advantages in relation to the weighting method, especially in the presence of discrete variables (Mixed Integer or Pure Integer problems). The $\varepsilon$-constraint approach, first introduced by Haimes, et al. (1971), generates efficient solutions by converting all but one objective functions into constraints of the model (Haimes et al., 1971). The augmented $\varepsilon$-constraint approach (AUGMECON) developed by Mavrotas (2009) can be used in order to remove weakly efficient solutions generated when applying the classical $\varepsilon$-constraint approach. (Hombach and Walther, 2015). AUGMECON is extended by Mavrotas and Florios (2013) in AUGMECON2 method, which in the case of MOIP and 0-1 Multiciteria Ordered Median Problems (MOMP) problems (i.e. MOIP problems with only $0-1$ variables as integer variables, which constitute the vast majority of MOIP problems), can be used to produce the exact (or complete) Pareto set, i.e. all the Pareto optimal solutions (Mavrotas and Florios, 2013). For calculating the exact Pareto set in MOIP problems with integer objective function coefficients, the AUGMECON2 method has been coded in the General Algebraic Modeling System (GAMS).

In the literature, several versions of the $\varepsilon$-constraint method have appeared trying to improve its performance or adapt it to a specific type of problems like MOIP problems (Keshavarz and Toloo, 2015; Mazidi et al., 2016). The technical novelties of the AUGMECON 2 method are: (a) construction of the payoff matrix in order to calculate the ranges of every objective functions; (b) avoidance of weakly Pareto optimal solutions by transforming the objective function constraints to equalities, by explicitly incorporating the appropriate slack (for minimisation objectives) or surplus (for maximisation objectives) variables; (c) early exit from the loops in order to treat the case of infeasibilities; and (d) less computational time (Xidonas et al., 2016b). These improvements are more effective when the problem contains discrete variables and the feasible region is non-convex (Mavrotas and Florios, 2013).

In the following, the augmented $\varepsilon$-constrained method (AUGMECON 2) developed by Mavrotas (2009) is implemented in order to solve the bi-objective optimisation model of technological R\&D selection. Thus, all efficient solutions are obtained and the calculation of weakly efficient solutions is avoided.

[Type here] 
This document is the Accepted Manuscript version of a Published Work that appeared in final form in:

Forouli A., Doukas H., Nikas A., Sampedro J., Van de Ven D.-J. 2019. Identifying optimal technological portfolios for European power generation towards climate change mitigation: A robust portfolio analysis approach. Utilities Policy. 57. 33-42. DOI (10.1016/j.jup.2019.01.006).

(C) 2019 Elsevier Ltd. All rights reserved.

This manuscript version is made available under the CC-BY-NC-ND 3.0 license

http://creativecommons.org/licenses/by-nc-nd/3.0/

\section{Robustness Analysis}

Monte Carlo simulation

As already outlined, it is true that several uncertain factors (costs, demand function, prices, system operation, regulatory measures, etc.) are present in electricity markets, affecting the agents participating in them. The risks affect different elements in the form of uncertainty and variability, including financial and regulatory aspects; issues related to climate change; societal acceptance of certain technologies; conditioning factors related to energy security; and transaction costs (Jano-Ito and Crawford-Brown, 2017). Various methods have been proposed for dealing with this uncertainty, the most common ones being fuzzy programming, chanceconstrained programming, robust programming, and stochastic programming (Mavrotas and Pechak, 2013).

In this work, the implied uncertainty is considered as being of stochastic nature. Each uncertain parameter is characterised by a probability distribution. Using Monte Carlo simulation, various probability distributions for uncertain parameters can be contemplated. Subsequently, a Monte Carlo simulation samples the values from these distributions, and the Mathematical Programming (MP) models with the sampled values are solved. This process is repeated $T$ times (with $T$ being a large number, for example $T=1,000$ ) in order to have an adequate sample for drawing robust conclusions. This pair of sampling and optimisation is the core of calculations. For example, if the number of Monte Carlo simulations is set to 1,000, then 1,000 sampling and optimisation runs will be carried out. The output of this process will be 1,000 different Pareto fronts of optimal portfolios, based on the sampling of the model's parameters.

Iterative Trichotomic Approach

In order to build robust optimal portfolios, this study uses the main idea of the iterative trichotomic approach (ITA) (Mavrotas and Pechak 2013). The trichotomic approach was first introduced in integer programming, to deal with uncertainty in single objective problems of project portfolio selection. Xidonas et al. extend the applicability of ITA to the case of multiobjective optimisation (Xidonas et al., 2016a). The difference with the original ITA of Mavrotas is that the "multiobjective" version of ITA provides information about the degree of certainty for inclusion of a specific portfolio in the final Pareto set, expanding thus its application area from project level to portfolio level.

This study properly links the implementation of ITA in a bi-objective model to provide Pareto Optimal Portfolios (POPs), among which the most preferred one is selected by the decision makers. In this way, the decision makers' selection is supported by specific indicators on the degree of certainty regarding the portfolios' Pareto optimality. As described in the above section, uncertainty is incorporated using probability distributions for R\&D technologies' performance, which is the major driver of the optimisation. Each Monte Carlo sampling 
This document is the Accepted Manuscript version of a Published Work that appeared in final form in:

Forouli A., Doukas H., Nikas A., Sampedro J., Van de Ven D.-J. 2019. Identifying optimal technological portfolios for European power generation towards climate change mitigation: A robust portfolio analysis approach. Utilities Policy. 57. 33-42. DOI (10.1016/j.jup.2019.01.006).

(C) 2019 Elsevier Ltd. All rights reserved.

This manuscript version is made available under the CC-BY-NC-ND 3.0 license http://creativecommons.org/licenses/by-nc-nd/3.0/

provides a Pareto of optimal portfolios. The ITA approach proposes an "iterative" process developed in a series of computation round. In each computation round all POPs $p$ are allocated in three sets: the green set $(G)$, the red set $(R)$ and the grey set $(Y)$. Eventually, in each round, ITA divides the optimal portfolios in the three subsets $(G, R, Y)$ depending on their degree of participation in the $T$ generated Pareto sets. The green set includes the portfolios $p$ that are present in all Pareto sets $\left(P S_{1}, \ldots, P S_{T}\right)$ of the computation round, the red set includes the portfolios that were produced in the initial computational round but are not present in any of $T$ Pareto sets in current computational round and the grey set includes portfolios that are present in some of $T$ Pareto sets. In the first round (round with maximum uncertainty), a maximum number of portfolios is generated as candidate final POPs. The first round results only in green and grey sets, as there is no portfolio to be excluded (red set) from the Pareto set. In subsequent rounds some of these initial optimal portfolios are not present anymore in any of the $T$ Pareto sets, so they join the red set. Along this process, the uncertainty of the model's parameters (objective functions' coefficients) is reduced (e.g. by reducing the standard deviation of a normal probability distribution or shrinking the interval of a uniform probability distribution). As the uncertainty is reduced, more portfolios from the grey set move to the green one (appear in all Pareto sets). Eventually, and as uncertainty gradually decreases, each one of the initial POPs is characterised as red or green, resulting in obtaining the final Pareto set.

\section{Proposed integrated approach}

Each of the above described models has certain concrete advantages in supporting decision making in environmental and energy planning as well as climate policy. This paper makes an endeavor to synthesise these models in an integrated approach and provide stakeholders with a fully featured, robust decision support framework. The first step features the formulation of the PA model, in the aim of supporting policymakers by providing them with a set of optimal alternatives (Pareto set), instead of one optimal solution, which is rarely the case in this problem domain. To formulate the bi-objective problem, suitable objective functions (optimisation criteria) and constraints must be first defined. An appropriate programming method is selected to carry out the multi-objective optimisation, resulting in a Pareto optimal set of efficient portfolios. Here the AUGMECON2 method is suggested for the multi-objective modelling part. The second step requires the application of the GCAM model (or any similar IAM) in order to extract key quantitative information on the climate-energy bi-objective problem to be solved. The outputs of the IAM can be inserted as parameters in the bi-objective model (e.g. as objective function coefficients, constraints, etc.). This second step ensures that the information arising from the GCAM model is further utilised and exploited to give even more concrete and concise insights for decision making. In the next step, the optimisation process is enhanced with robustness features. The selected method of multi-objective modelling, namely the AUGMECON2 method, supports incorporation of stochastic uncertainty by appropriately 
This document is the Accepted Manuscript version of a Published Work that appeared in final form in:

Forouli A., Doukas H., Nikas A., Sampedro J., Van de Ven D.-J. 2019. Identifying optimal technological portfolios for European power generation towards climate change mitigation: A robust portfolio analysis approach. Utilities Policy. 57. 33-42. DOI (10.1016/j.jup.2019.01.006).

(C) 2019 Elsevier Ltd. All rights reserved.

This manuscript version is made available under the CC-BY-NC-ND 3.0 license http://creativecommons.org/licenses/by-nc-nd/3.0/

applying Monte Carlo simulation and the ITA technique. Finally, these three discrete steps lead to a specific, well-defined set of robust optimal portfolios from which the most preferable can be selected by the decision makers and could subsequently be used by a linked deterministic model. This kind of information is highly important for the decision makers when selecting technological portfolios that feature a high degree of uncertainty regarding their Pareto optimality. The proposed approach is summarised in concrete steps in the following figure (Figure 2).

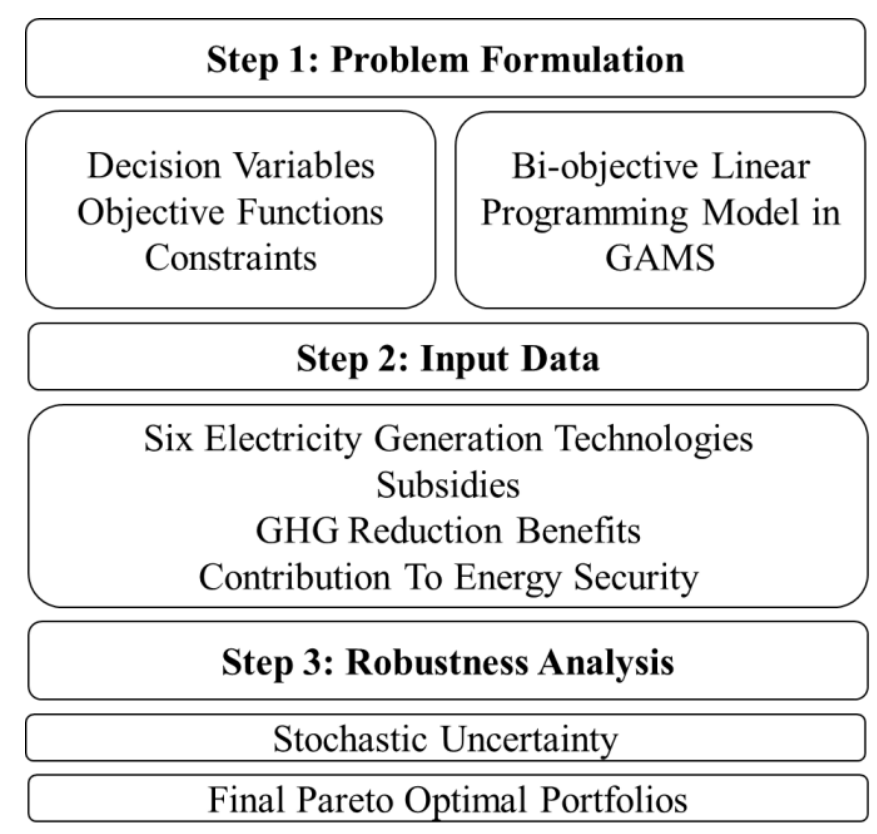

Figure 2: Proposed approach steps

The expected added value of the proposed integration orbits around the gap between the output of formalised modelling frameworks and the actual policy questions that these are asked to help answer. The integrated assessment modelling component, in this implementation of the GCAM model, helps represent and evaluate the behaviour and interactions of the energy system with fossil fuel emissions, also providing insights into the resulting energy security associated with different power generation technologies and respective subsidy levels. However, the modelling outcomes cover the contributions and effects of individual electricity generation technologies, while decision makers must essentially evaluate the technological energy mix as a whole. Through the implementation of the PA module, the data resulting from the GCAM model are further evaluated in the form of portfolios, based on multiple optimisation criteria. This enables policymakers to select over a range of optimal portfolios, as generated in the Pareto Front, depending on the levels of the two optimisation criteria that better fulfill their needs.

[Type here] 
This document is the Accepted Manuscript version of a Published Work that appeared in final form in:

Forouli A., Doukas H., Nikas A., Sampedro J., Van de Ven D.-J. 2019. Identifying optimal technological portfolios for European power generation towards climate change mitigation: A robust portfolio analysis approach. Utilities Policy. 57. 33-42. DOI (10.1016/j.jup.2019.01.006).

(C) 2019 Elsevier Ltd. All rights reserved.

This manuscript version is made available under the CC-BY-NC-ND 3.0 license http://creativecommons.org/licenses/by-nc-nd/3.0/

Furthermore, given the need for robust decision making, cultivated by the uncertain dynamics of the energy market and long-term future developments, the proposed approach eventually attempts to evaluate the resulting technological R\&D portfolios in light of uncertainty. This is done by assessing the impact of stochastic uncertainty in the optimal portfolios resulting from the PA component.

\section{Application Results and Discussion}

\section{Step 1 - Problem Formulation}

This paper suggests an integrated approach to evaluate the performance of electricity generation technologies on an EU-27 level and in a timescale until 2050. To achieve this, a bi-objective programming model for PA under uncertainty is utilised so that numerical results provided by the GCAM model can be appropriately aggregated.

The analysis particularly focuses on six low-carbon generation technologies $(i=1 \ldots 6)$, namely T1: photovoltaics (PV), T2: concentrated solar power (CSP), T3: wind, T4: nuclear, T5: biomass and T6: carbon capture and storage (CCS). We focus on these six technologies as they are, compared to conventional technologies, highly relevant for subsidisation in the near future towards reducing $\mathrm{CO}_{2}$ emissions at the EU level. Furthermore, geothermal or other technologies with smaller potential, however relevant, are not included to avoid complicating the portfolio analysis.

Input from the GCAM model provides ten different subsidy values $(j=1 \ldots 10)$, calculated as a multiplication of the unitary subsidies (\$/GJ of electricity output, from 10 to $100 \%$ of the LCOE in 2010) with the electricity consumption of the analysed technology in 2050. Stemming from the fact that the short-term impact of policies promoting new technologies is considerably reduced by the installed power capacity in the base years of the analysis, the robust portfolio analysis is applied in the results until 2050 so that the effects of the technologies can be clearly visible.

The problem is solved according to two optimisation criteria. The first objective function seeks to maximise the reduction of GHG emissions corresponding to specific budget investment:

$$
\text { maximise } Z_{2}=\sum_{i=1}^{6} \sum_{j=1}^{10} \operatorname{GHGreduction}(i, j) * B(i, j)
$$

Where GHGreduction $(i, j)$ is the emissions reduction achieved by the $i_{\text {th }}$ technology under budget option $j$.

The second objective is to maximise the system's energy security again in relation to the allocated budget. 
This document is the Accepted Manuscript version of a Published Work that appeared in final form in:

Forouli A., Doukas H., Nikas A., Sampedro J., Van de Ven D.-J. 2019. Identifying optimal technological portfolios for European power generation towards climate change mitigation: A robust portfolio analysis approach. Utilities Policy. 57. 33-42. DOI (10.1016/j.jup.2019.01.006).

(c) 2019 Elsevier Ltd. All rights reserved.

This manuscript version is made available under the CC-BY-NC-ND 3.0 license

http://creativecommons.org/licenses/by-nc-nd/3.0/

$$
\text { maximise } Z_{1}=\sum_{i=1}^{6} \sum_{j=1}^{10} \operatorname{Security}(i, j) * B(i, j)
$$

Where Security $(i, j)$ is the contribution to energy security of technology $i$ under budget option $j$.

The objective functions' coefficients, namely emissions reduction (GHGreduction $(i, j))$ and energy security (Security $(i, j)$ ) are collected as an outcome of the GCAM model. The decision variables of the model are binary. The binary variables $B i, j$ represent the existence of the " $i$ technology and $j$ subsidy" options corresponding to the specific technology selection $((B i, j=1)$ or $\operatorname{not}(B i, j=0))$.

The model also incorporates five specific constraints.

1. First of all, a budget constraint is used in order to secure that the cumulative cost of approved applications does not exceed a previously defined, overall budget.

$$
\sum_{i=1}^{6} \sum_{j=1}^{10} \operatorname{Subsidy}(i, j) * B(i, j) \leq \text { maxBudget }
$$

Where maxBudget is the total available budget and $\operatorname{Subsidy}(i, j)$ the $j_{\text {th }}$ cost option of technology $i$. In the specific application, the available budget is set equal to $35 \%$ of the maximum cost of all six technologies.

2. This application also defines a minimum bound of emissions reduction to be achieved by the portfolio.

$$
\sum_{i=1}^{6} \sum_{j=1}^{10} \operatorname{GHGreduction}(i, j) * B(i, j) \geq \text { minEmissions }
$$

Where minEmissions is the minimum required reduction of GHG emissions and GHGreduction $(i, j)$ the emissions reduction when selecting the $j_{\text {th }}$ cost option of technology $i$. The emission reduction target is set equal to $40 \%$ of the emissions reduction that would be achieved if all technologies were subsidised at $100 \%$ of their total cost.

3. Specific bounds are imposed to control the distribution of budget across the energy generation technologies, and with a focus on specific energy sources. In particular, it is considered preferable that nuclear projects not dominate a portfolio, as such projects are not supported in several countries of the EU. This condition is expressed with the

[Type here] 
This document is the Accepted Manuscript version of a Published Work that appeared in final form in:

Forouli A., Doukas H., Nikas A., Sampedro J., Van de Ven D.-J. 2019. Identifying optimal technological portfolios for European power generation towards climate change mitigation: A robust portfolio analysis approach. Utilities Policy. 57. 33-42. DOI (10.1016/j.jup.2019.01.006).

(C) 2019 Elsevier Ltd. All rights reserved.

This manuscript version is made available under the CC-BY-NC-ND 3.0 license http://creativecommons.org/licenses/by-nc-nd/3.0/

following constraint, defined as "nuclear energy is not allowed to be receive more than $30 \%$ of the total available budget":

$$
\text { Subsidy }(\text { Nuclear }, j) * B(\text { Nuclear }, j)<0.3 * \operatorname{maxBudget}, \forall j=1 \ldots 10
$$

4. The next constraint allows for the determination of specific energy technology preferences. Through this particular constraint wind and photovoltaic energy are preferred as dominant technological sources, and the allocation of budget in such generation technologies "must thus collectively equal to more than $40 \%$ of the total available budget".

$\operatorname{Subsidy}(P V, j) * B(P V, j)+\operatorname{Subsidy}($ wind,$j) * B($ wind,$j) \geq 0.4 \operatorname{maxBudget}, \forall j=1 \ldots 10$

5. In order to assure that only one budget option is allocated per technology, the following constraint is added.

$$
\sum_{j=1}^{10} B(i, j) \leq 1, \forall i=1 \ldots 6
$$

The constraint guarantees that, in the case of purchasing a new technology with a certain amount of budget, purchasing the same technology with another amount of budget is not possible.

\begin{tabular}{|c|c|}
\hline Decision Variables & Description \\
\hline$B i, j$ & $\begin{array}{l}\text { If } B i, j=1 \text { the pair " } i \text { technology and } j \\
\text { subsidy" is approved. } \\
\text { Otherwise if } B i, j=0 \text { the corresponding } \\
\text { technology-subsidy pair is rejected. }\end{array}$ \\
\hline Objective Functions & Description \\
\hline maximise $Z_{1}$ & $\begin{array}{l}\text { maximise the reduction of GHG emissions } \\
\text { corresponding to specific subsidy }\end{array}$ \\
\hline maximise $Z_{2}$ & $\begin{array}{l}\text { maximise the system's energy security } \\
\text { corresponding to specific subsidy }\end{array}$ \\
\hline Constraints & Description \\
\hline Budget constraint & $\begin{array}{l}\text { Overall implementation cost must be less } \\
\text { than } 35 \% \text { of maximum (i.e. if all } \\
\text { technologies were subsidised at } 100 \% \text { ). }\end{array}$ \\
\hline
\end{tabular}

Table 1: Problem Definition - overview

[Type here] 
This document is the Accepted Manuscript version of a Published Work that appeared in final form in:

Forouli A., Doukas H., Nikas A., Sampedro J., Van de Ven D.-J. 2019. Identifying optimal technological portfolios for European power generation towards climate change mitigation: A robust portfolio analysis approach. Utilities Policy. 57. 33-42. DOI (10.1016/j.jup.2019.01.006).

(C) 2019 Elsevier Ltd. All rights reserved.

This manuscript version is made available under the CC-BY-NC-ND 3.0 license http://creativecommons.org/licenses/by-nc-nd/3.0/

Emissions reduction target

\section{Nuclear constraint}

Wind and PV dominance

Unique subsidy constraint
Overall emissions reduction must be greater than $40 \%$ of maximum (i.e. if all technologies were subsidised at $100 \%$ ).

Participation of Nuclear power cannot be greater than $30 \%$.

More than $40 \%$ of the total available budget must be allocated to wind and PV energy.

One budget option can be allocated per technology.

Stemming from the above analysis it is important to highlight that the contribution of each technology in energy security and emission reduction is linked with a certain implementation cost (variable $j$ ). By that, and considering 1) the overall maximum budget constraint which the implementation cost of all technologies must not exceed and 2) the two objective functions aiming to achieve the maximum of energy security and emissions reduction, the model identifies the alternatives (portfolios of technologies) that give the maximum contribution to energy security and emission reduction, with a minimum of budget investment, thus also featuring the inherent notion of "cost-effectiveness".

\section{Step 2 - Input Data}

The study makes use of GCAM in order to quantify the GHG reduction benefits and the contribution of individual technologies to EU's energy security, for different budget options (subsidies). As required in the previous step, ten subsidy levels are defined and their individual interaction to GHG reduction and contribution to energy security is assessed for each of the six technologies, based on the GCAM model.

For calculating the subsidy, the unitary subsidies (\$/energy unit, from 10 to $100 \%$ of the energy technology Levelised Cost of Energy - LCOE) are multiplied with electricity consumption of the examined technology in 2050. LCOE is calculated from a mixed set of data on capital and maintenance costs, efficiency, capacity factors, etc. The modelling assumptions used in this application are documented in Muratori et al. (2017). The subsidisation procedure to the EU27 region is applied in the period from 2020 to 2050 by adding up the results for EU12 and EU15, which are the two EU regions predefined in the GCAM 4.3 model.

Energy security is calculated as the energy produced in the region divided by the total energy consumed in the region. Energy consumption data for the base years (up to 2010) is provided by the International Energy Agency (IEA) and simulated by the GCAM model until 2050.

EU-27 future fossil fuel production has been taken from the estimates of IEA. Biomass local production and consumption are also extracted from the model. Finally, it is assumed that all 
This document is the Accepted Manuscript version of a Published Work that appeared in final form in:

Forouli A., Doukas H., Nikas A., Sampedro J., Van de Ven D.-J. 2019. Identifying optimal technological portfolios for European power generation towards climate change mitigation: A robust portfolio analysis approach. Utilities Policy. 57. 33-42. DOI (10.1016/j.jup.2019.01.006).

(C) 2019 Elsevier Ltd. All rights reserved.

This manuscript version is made available under the CC-BY-NC-ND 3.0 license http://creativecommons.org/licenses/by-nc-nd/3.0/

of the renewable (solar, wind, geothermal and hydropower) and nuclear energy is produced and consumed inside the region.

Table 2: Maximum contributions per technology

\begin{tabular}{lcc}
\hline Technology & Maximum Energy Security & Maximum GHG emissions reduction \\
\hline PV & $80.9 \%$ & $510.86 \mathrm{MTC}$ \\
CSP & $53.2 \%$ & $93.20 \mathrm{MTC}$ \\
Wind & $70.0 \%$ & $296.55 \mathrm{MTC}$ \\
Nuclear & $95.1 \%$ & $730.20 \mathrm{MTC}$ \\
Biomass & $48.6 \%$ & $322.08 \mathrm{MTC}$ \\
CCS & $48.0 \%$ & $157.93 \mathrm{MTC}$ \\
\hline
\end{tabular}

The most interesting finding of this step is that, as expected, the subsidisation of different clean energy sources would result in positive and substantial emission reductions. However, the features of each technology (such as cost, intermittency or lifetime) cause $\mathrm{CO}_{2}$ reduction paths to differ among the technologies.

Considering the assumption that renewable and nuclear energy is produced and consumed within the region, subsidising those sources benefits energy security. Nevertheless, energy security decreases when the budget is spent on CCS and biomass. This is consistent because supplies of fossil and bio-energy are limited, so the region should import these resources from abroad if regional demand increases. Consequently, although subsidising CCS or biomass would entail significant $\mathrm{CO}_{2}$ reductions per unit of subsidy, it might also result in energy security related problems.

\section{Step 3 - Uncertainty Management and Robustness Assessment}

After selecting the input data the PA model as described in Step 1 is run, resulting in a set of optimal portfolios, i.e. the Pareto Front, the robustness of which is assessed in this step. The Pareto Front is illustrated in Figure 3, in which the most robust portfolios are further highlighted. This is easier to understand when considering that Figure 3 corresponds to the $6^{\text {th }}$ round of the ITA implementation, where a standard deviation of $\sigma=0 \%$ is reflected, corresponding to the Pareto Front when no uncertainty is considered, as described below.

[Type here] 
This document is the Accepted Manuscript version of a Published Work that appeared in final form in:

Forouli A., Doukas H., Nikas A., Sampedro J., Van de Ven D.-J. 2019. Identifying optimal technological portfolios for European power generation towards climate change mitigation: A robust portfolio analysis approach. Utilities Policy. 57. 33-42. DOI (10.1016/j.jup.2019.01.006).

(C) 2019 Elsevier Ltd. All rights reserved.

This manuscript version is made available under the CC-BY-NC-ND 3.0 license http://creativecommons.org/licenses/by-nc-nd/3.0/

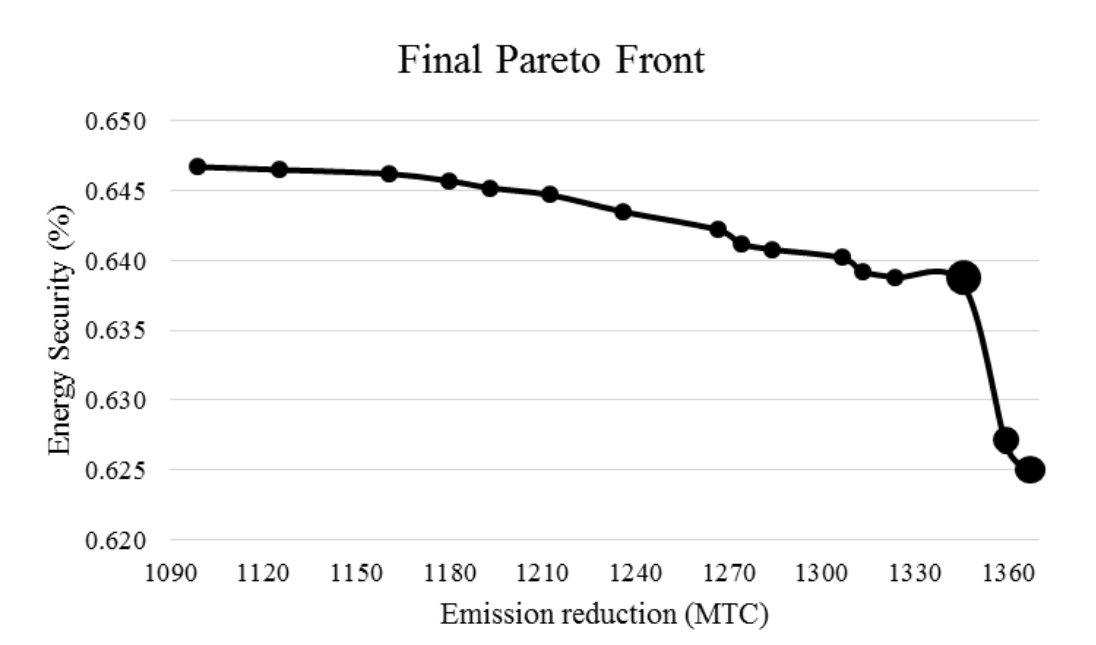

Figure 3: Final Pareto front of robust portfolios

The uncertainty characterising the estimation of technology performance, in reducing GHG emissions as well as contributing to energy security, is expressed by introducing normal distributions for relevant technologies' values. Specifically, the mean value for the normal distributions is set equal to the estimated values as obtained from the runs of the GCAM model, and the standard deviation of the iterations equal to $5 \%, 4 \%, 3 \%, 2 \%, 1 \%$, and $0 \%$ corresponding to six ITA rounds. The whole process (model building, random sampling, Pareto set generation) is implemented within the GAMS platform. 1,000 Monte Carlo iterations are performed for each ITA computation round. It must be noted that, in the specific application, a 94\% acceptance threshold for the green set is determined (if a portfolio is present in $94 \%$ of Pareto sets i.e. in 940 out of 1,000 ).

The results of multi-objective ITA are shown in Table 3. There are in total 842 POPs that participate in 1,000 Pareto sets of the initial round. At subsequent iterations, the standard deviation of sampling distributions is reduced as shown in the first column of Table 3. Eventually, on the last round the final Pareto set is obtained; this comprises 16 POPs of R\&D electricity generation technologies. The additional information that ITA gives is that it reveals which of these 16 portfolios can be considered more certain than others. The degree of certainty for each portfolio is directly related to the corresponding round that it enters the green set (the earlier the portfolio enters the green set, the more certain the decision makers is about its Pareto optimality).

Table 3: ITA results

\begin{tabular}{lllll}
\hline & & Green & Red & Grey \\
\hline $\boldsymbol{\sigma}=\mathbf{5} \%$ & Round 1 & 0 & 0 & 842
\end{tabular}

[Type here] 
This document is the Accepted Manuscript version of a Published Work that appeared in final form in:

Forouli A., Doukas H., Nikas A., Sampedro J., Van de Ven D.-J. 2019. Identifying optimal technological portfolios for European power generation towards climate change mitigation: A robust portfolio analysis approach. Utilities Policy. 57. 33-42. DOI (10.1016/j.jup.2019.01.006).

(c) 2019 Elsevier Ltd. All rights reserved.

This manuscript version is made available under the CC-BY-NC-ND 3.0 license http://creativecommons.org/licenses/by-nc-nd/3.0/

$\begin{array}{lllll}\boldsymbol{\sigma}=\mathbf{4} \% & \text { Round 2 } & 0 & 321 & 521 \\ \boldsymbol{\sigma}=\mathbf{3} \% & \text { Round 3 } & 1 & 546 & 295 \\ \boldsymbol{\sigma}=\mathbf{2} \% & \text { Round 4 } & 2 & 704 & 136 \\ \boldsymbol{\sigma}=\mathbf{1} \% & \text { Round 5 } & 3 & 779 & 60 \\ \boldsymbol{\sigma}=\mathbf{0} \% & \text { Round 6 } & 16 & 826 & 0\end{array}$

The final set of the 16 POPs with the most robust portfolios illustrated by bubbles of greater size is shown in Figure 3 and further elaborated in Figure 4.

[Type here] 
This document is the Accepted Manuscript version of a Published Work that appeared in final form in:

Forouli A., Doukas H., Nikas A., Sampedro J., Van de Ven D.-J. 2019. Identifying optimal technological portfolios for European power generation towards climate change mitigation: A robust portfolio analysis approach. Utilities Policy. 57. 33-42. DOI (10.1016/j.jup.2019.01.006).

(c) 2019 Elsevier Ltd. All rights reserved.

This manuscript version is made available under the CC-BY-NC-ND 3.0 license http://creativecommons.org/licenses/by-nc-nd/3.0/
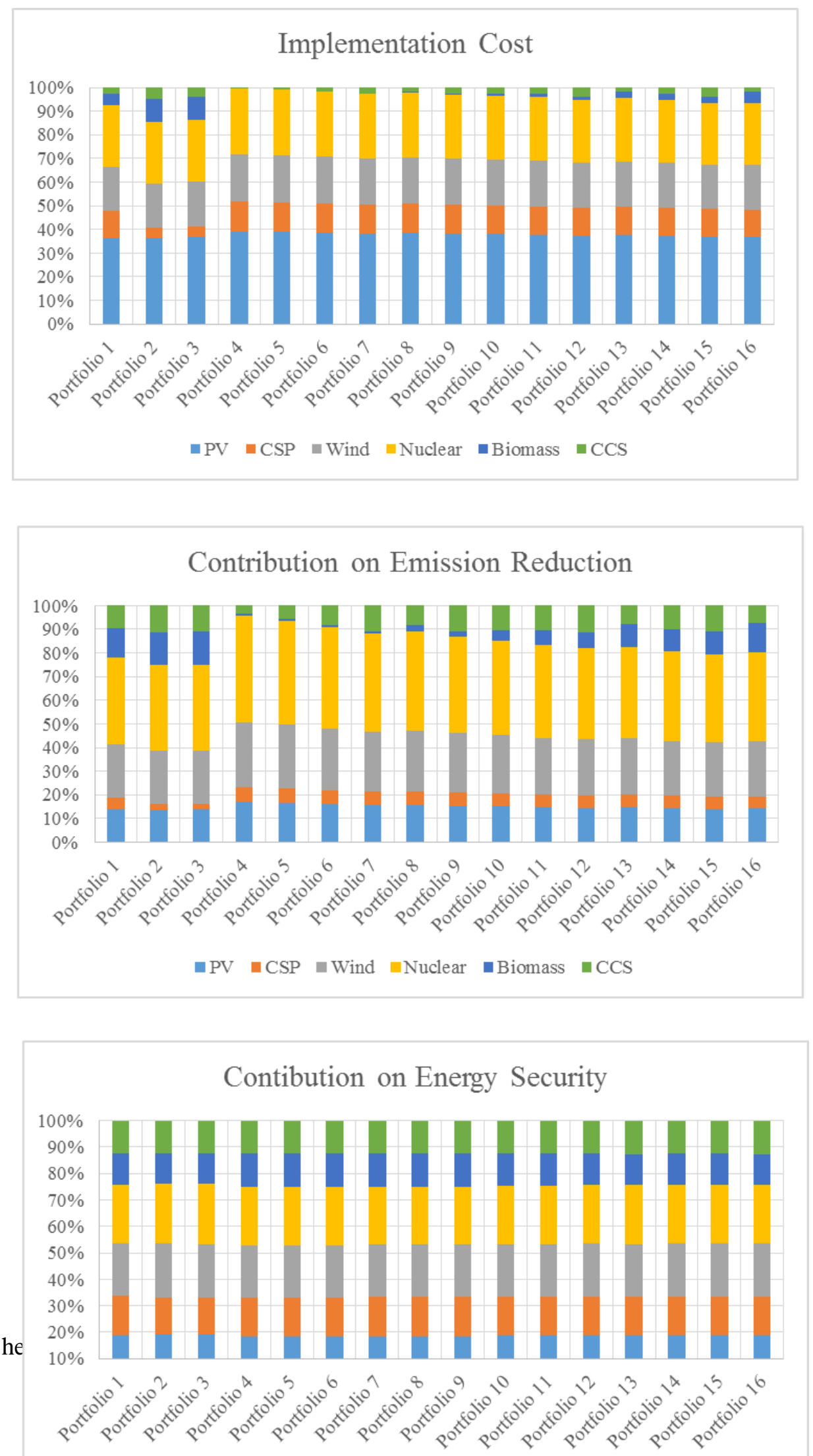
This document is the Accepted Manuscript version of a Published Work that appeared in final form in:

Forouli A., Doukas H., Nikas A., Sampedro J., Van de Ven D.-J. 2019. Identifying optimal technological portfolios for European power generation towards climate change mitigation: A robust portfolio analysis approach. Utilities Policy. 57. 33-42. DOI (10.1016/j.jup.2019.01.006).

(C) 2019 Elsevier Ltd. All rights reserved.

This manuscript version is made available under the CC-BY-NC-ND 3.0 license

http://creativecommons.org/licenses/by-nc-nd/3.0/

Figure 4: Technology contribution in the 16 robust portfolios

The portfolio that corresponds to the maximum robustness exhibits energy security of $63.82 \%$ and emission reduction of 1,345.8 MTC and is further elaborated in Table 4. It is noteworthy that CCS and biomass shares in the portfolio budget are rather small, despite featuring high contribution to emissions reduction; regardless of the capacity to invest more, larger investments in these technologies would negatively affect the energy security-emissions reduction tradeoff. The second and third most robust portfolios involve subsidies for CSP energy in a significantly lesser amount, while subsidies in biomass and CCS-equipped plants are doubled. However, contribution of PV, wind and nuclear in the investment mix appears to be consistent among the robust portfolios. The final Pareto Front also indicates a reduction on energy security among the robust portfolios. This is justified by the fact that, as biomass is more likely to be imported, larger investments in this technology would have a negative impact on energy security. The same applies for combustible resources and, thus, CCS technologies.

Table 4: Technologies participation in robust portfolios

\begin{tabular}{cccc}
\hline Technology & $\begin{array}{c}\text { Contribution to } \\
\text { portfolio's total } \\
\text { energy security }\end{array}$ & $\begin{array}{c}\text { Contribution to } \\
\text { portfolio's total } \\
\text { emissions reduction }\end{array}$ & $\begin{array}{c}\text { Share of total } \\
\text { portfolio budget }\end{array}$ \\
\hline PV & \multicolumn{3}{c}{ Portfolio 1 } \\
CSP & $18.80 \%$ & $13.91 \%$ & $36.41 \%$ \\
Wind & $14.83 \%$ & $5.03 \%$ & $11.61 \%$ \\
Nuclear & $22.25 \%$ & $22.53 \%$ & $18.49 \%$ \\
Biomass & $11.60 \%$ & $36.79 \%$ & $25.81 \%$ \\
CCS & $12.54 \%$ & $12.10 \%$ & $5.16 \%$ \\
\hline \multicolumn{5}{c}{ Ranges of the technologies' contributions in robust portfolios $1-16$} \\
\hline PV & $18.56 \%-19.20 \%$ & $13.71 \%-17.05 \%$ & $36.41 \%-39.19 \%$ \\
CSP & $13.78 \%-14.83 \%$ & $2.59 \%-6.16 \%$ & $4.36 \%-12.51 \%$ \\
Wind & $19.72 \%-20.40 \%$ & $22.20 \%-27.60 \%$ & $18.49 \%-19.92 \%$ \\
Nuclear & $21.96 \%-22.72 \%$ & $36.25 \%-45.06 \%$ & $25.81 \%-27.79 \%$ \\
Biomass & $11.52 \%-12.55 \%$ & $0.85 \%-14.09 \%$ & $0.13 \%-9.89 \%$ \\
CCS & $12.27 \%-12.67 \%$ & $3.21 \%-11.44 \%$ & $0.45 \%-4.87 \%$ \\
\hline
\end{tabular}

\section{Conclusion}

This paper links two models used to explore potential strategies of climate change mitigation and energy planning, namely an IAM with a robust PA model. The application particularly focuses on the evaluation of EU-27 electricity generation options in a long-term perspective

[Type here] 
This document is the Accepted Manuscript version of a Published Work that appeared in final form in:

Forouli A., Doukas H., Nikas A., Sampedro J., Van de Ven D.-J. 2019. Identifying optimal technological portfolios for European power generation towards climate change mitigation: A robust portfolio analysis approach. Utilities Policy. 57. 33-42. DOI (10.1016/j.jup.2019.01.006).

(C) 2019 Elsevier Ltd. All rights reserved.

This manuscript version is made available under the CC-BY-NC-ND 3.0 license http://creativecommons.org/licenses/by-nc-nd/3.0/

(2050). The analysis properly integrates the GCAM model results into a portfolio generation model, while also treating exogenous uncertainty stochastically. The outcome of the proposed approach is a set of optimal electricity generation portfolios, among which the most robust is selected.

The results give an indication on how subsidisation among the energy generation technologies should be allocated. The analysis shows that technologies like PV, wind and nuclear energy must be prioritised and subsidised; while investments in biomass, CCS and CSP appear to contribute less to EU's power generation mix, when considering the given time horizon and both of the problem's objectives, i.e. overall GHG emissions reduction and energy security maximisation. Further analysis of the inherent stochastic uncertainty indicates that the three technologies with the largest shares in the portfolio budget also appear to be the most robust, in the context of this particular problem. Policymakers are therefore provided with clear recommendations regarding $\mathrm{PV}$, wind and nuclear, as well as flexibility to select among different options in CCS, CSP and biomass.

It is important to note that the calculated outputs of this analysis are strongly dependent on the modelling assumptions; the results should be carefully interpreted, while taking into consideration the assumptions outlined and referred to in the "Input Data" section. For instance, introducing other power generating (e.g. geothermal) or energy efficiency technologies, with substantial potential relevant for the European region, could have an impact on the resulting subsidisation portfolios and therefore constitute an interesting future direction of the proposed research.

Further prospects towards enriching the proposed methodological framework potentially include integrating the PA model with other climate-economy models, which cover a complete set of relevant emissions and a different level of granularity from the GCAM model. This can be extended to the assumed economic approach of the linked IAM, by additionally integrating the PA component with general equilibrium or macroeconometric models, and shifting the focus from aspects that partial equilibrium modelling highlights, thus maximising the robustness of the framework's findings. It is also interesting to use nationally disaggregated data and proceed to carrying out country-level analyses based on the methodological framework developed and presented in this study, either with GCAM or with other climate-economy modelling frameworks like the PRIMES or JRC-EU-TIMES models for modelling on European countries.

Finally it should be noted that, although the proposed methodological framework is in the context of emerging scientific paradigms in support of climate policymaking that highlight the need to reduce or help understand uncertainty (Doukas et al., 2018), by providing information on the level of certainty associated with resulting policy options thereby maximising the 
This document is the Accepted Manuscript version of a Published Work that appeared in final form in:

Forouli A., Doukas H., Nikas A., Sampedro J., Van de Ven D.-J. 2019. Identifying optimal technological portfolios for European power generation towards climate change mitigation: A robust portfolio analysis approach. Utilities Policy. 57. 33-42. DOI (10.1016/j.jup.2019.01.006).

(C) 2019 Elsevier Ltd. All rights reserved.

This manuscript version is made available under the CC-BY-NC-ND 3.0 license http://creativecommons.org/licenses/by-nc-nd/3.0/

robustness of the results and adding value for policymakers, the latter are not actively involved in the study. There is huge potential in involving both policymakers and other stakeholder groups in policy analysis, in order to understand the motives and strategies of all actors relevant in the required transformations (Turnheim et al., 2015), as well as exploit their expertise to bridge knowledge gaps and further reduce the various uncertainties in this domain (Nikas et al., 2017). In this respect, it would be interesting to work with stakeholders and decision makers in climate action, by expanding the method to some other regions and/or technologies, or eliminating any of the used ones; as well as to better incorporate real-world context in the modelling assumptions, constraints and parameters of the modelling exercise.

\section{References}

Arvesen, A., Luderer, G., Pehl, M., Bodirsky, B.L., Hertwich, E.G., 2018. Deriving life cycle assessment coefficients for application in integrated assessment modelling. Environ. Model. Softw. 99, 111-125. https://doi.org/10.1016/j.envsoft.2017.09.010

Awerbuch, S., 2004. Portfolio-based electricity generation planning: implications for renewables and energy security. Prepared as part of a demonstration project funded by REEEP and UNEP and conducted in collaboration with ECN of The Netherlands, the basel agency for sustainable energy (BASE), and project partners: CDER (Morocco), IIE (Mexico) and TERI (India). http://www.awerbuch.com/shimonpages/shimondocs/unepfco_portfolio.pdf.

Awerbuch, S., Berger, M., 2003. Applying portfolio theory to EU electricity planning and policy-making, IEA/EET working paper, EET/2003/03. http://www.awerbuch.com/shimonpages/shimondocs/ieaportfolio.pdf.

Awerbuch, S., Yang, S., 2007. Efficient electricity generating portfolios for Europe: maximising energy security and climate change mitigation, A. Riess (Ed.), European investment bank papers, 12, EIB: Luxembourg (2007), pp. 8-37. http://www.eib.org/attachments/efs/eibpapers/eibpapers_2007_v12_n02_en.pdf.

Baker, E., Solak, S., 2011. Climate change and optimal energy technology R\&D policy. Eur. J. Oper. Res. 213, 442-454. https://doi.org/10.1016/j.ejor.2011.03.046

Cappuyns, V., 2016. Inclusion of social indicators in decision support tools for the selection of sustainable site remediation options. J. Environ. Manage., Sustainable Remediation 184, 45-56. https://doi.org/10.1016/j.jenvman.2016.07.035

Chiandussi, G., Codegone, M., Ferrero, S., Varesio, F.E., 2012. Comparison of multi-objective optimization methodologies for engineering applications. Comput. Math. Appl. 63, 912-942. https://doi.org/10.1016/j.camwa.2011.11.057

Collins, W.D., Craig, A.P., Truesdale, J.E., Di Vittorio, A.V., Jones, A.D., Bond-Lamberty, B., Calvin, K.V., Edmonds, J.A., Kim, S.H., Thomson, A.M., Patel, P., Zhou, Y., Mao, J., Shi, X., Thornton, P.E., Chini, L.P., Hurtt, G.C., 2015. The integrated Earth system model version 1: formulation and functionality. Geosci Model Dev 8, 2203-2219. https://doi.org/10.5194/gmd-8-2203-2015

[Type here] 
This document is the Accepted Manuscript version of a Published Work that appeared in final form in:

Forouli A., Doukas H., Nikas A., Sampedro J., Van de Ven D.-J. 2019. Identifying optimal technological portfolios for European power generation towards climate change mitigation: A robust portfolio analysis approach. Utilities Policy. 57. 33-42. DOI (10.1016/j.jup.2019.01.006).

(C) 2019 Elsevier Ltd. All rights reserved.

This manuscript version is made available under the CC-BY-NC-ND 3.0 license http://creativecommons.org/licenses/by-nc-nd/3.0/

Delarue, E., De Jonghe, C., Belmans, R., D'haeseleer, W., 2011. Applying portfolio theory to the electricity sector: Energy versus power. Energy Econ. 33, 12-23. https://doi.org/10.1016/j.eneco.2010.05.003

deLlano-Paz, F., Calvo-Silvosa, A., Antelo, S.I., Soares, I., 2017. Energy planning and modern portfolio theory: A review. Renew. Sustain. Energy Rev. 77, 636-651. https://doi.org/10.1016/j.rser.2017.04.045

Doukas, H., 2013. Modelling of linguistic variables in multicriteria energy policy support. European Journal of Operational Research. 227, 227-238. https://doi.org/10.1016/j.ejor.2012.11.026

Doukas, H., Nikas, A., González-Eguino, M., Arto, I., Anger-Kraavi, A., 2018. From Integrated to Integrative: Delivering on the Paris Agreement. Sustainability. 10, 2299. https://doi.org/10.3390/su10072299

E3MLab, 2014. Primes Model 2013-2014, Detailed model description. https://ec.europa.eu/clima/sites/clima/files/strategies/analysis/models/docs/primes_model_20132014_en.pdf

Ebi, K.L., Hallegatte, S., Kram, T., Arnell, N.W., Carter, T.R., Edmonds, J., Kriegler, E., Mathur, R., O’Neill, B.C., Riahi, K., Winkler, H., Vuuren, D.P.V., Zwickel, T., 2014. A new scenario framework for climate change research: background, process, and future directions. Clim. Change 122, 363-372. https://doi.org/10.1007/s10584-013-0912-3

Elton, E.J., Gruber, M.J., 1997. Modern portfolio theory, 1950 to date. J. Bank. Finance 21, 1743-1759. https://doi.org/10.1016/S0378-4266(97)00048-4

European Commission (EC), 2016a. The roadmap for transforming the EU into a competitive, lowcarbon economy by 2050. https://ec.europa.eu/clima/sites/clima/files/2050_roadmap_en.pdf.

European Commission (EC), 2016b. 2050 low-carbon economy. https://ec.europa.eu/clima/policies/strategies/2050_en (accessed 11.8.17).

Eurostat, 2017. Climate change - driving forces. http://ec.europa.eu/eurostat/statisticsexplained/index.php/Climate_change___driving_forces (accessed 11.10.17).

Fisher, B., Flannery, B.P., Marangoni, G., McJeon, H., Rogner, H., Hilaire, J., Edmonds, J., Riahi, K., Clarke, L., Tavoni, M., Bauer, N., Mi, R., Krey, V., 2014. Limited impact on decadal-scale climate change from increased use of natural gas. Nature 514, 482. https://doi.org/10.1038/nature13837

Hamilton, S.H., ElSawah, S., Guillaume, J.H.A., Jakeman, A.J., Pierce, S.A., 2015. Integrated assessment and modelling: Overview and synthesis of salient dimensions. Environ. Model. Softw. 64, 215-229. https://doi.org/10.1016/j.envsoft.2014.12.005

Hickey, E.A., Lon Carlson, J., Loomis, D., 2010. Issues in the determination of the optimal portfolio of electricity supply options. Energy Policy, Greater China Energy: Special Section with regular papers 38, 2198-2207. https://doi.org/10.1016/j.enpol.2009.12.006

Hombach, L.E., Walther, G., 2015. Pareto-efficient legal regulation of the (bio)fuel market using a biobjective optimization model. Eur. J. Oper. Res. 245, 286-295. https://doi.org/10.1016/j.ejor.2015.02.039

Intergovernmental Panel on Climate Change (IPCC), 2014. Climate Change 2014: Mitigation of Climate Change. Contribution of Working Group III to the Fifth Assessment Report of the Intergovernmental Panel on Climate Change [Edenhofer, O., R. Pichs-Madruga, Y. Sokona, E. Farahani, S. Kadner, K. Seyboth, A. Adler, I. Baum, S. Brunner, P. Eickemeier, B. Kriemann, J. Savolainen, S. Schlömer, C. 
This document is the Accepted Manuscript version of a Published Work that appeared in final form in:

Forouli A., Doukas H., Nikas A., Sampedro J., Van de Ven D.-J. 2019. Identifying optimal technological portfolios for European power generation towards climate change mitigation: A robust portfolio analysis approach. Utilities Policy. 57. 33-42. DOI (10.1016/j.jup.2019.01.006).

(C) 2019 Elsevier Ltd. All rights reserved.

This manuscript version is made available under the CC-BY-NC-ND 3.0 license http://creativecommons.org/licenses/by-nc-nd/3.0/

von Stechow, T. Zwickel and J.C. Minx (eds.)]. Cambridge University Press, Cambridge, United Kingdom and New York, NY, USA.

Jakeman, A.J., Letcher, R.A., 2003. Integrated assessment and modelling: features, principles and examples for catchment management. Environ. Model. Softw., Applying Computer Research to Environmental Problems 18, 491-501. https://doi.org/10.1016/S1364-8152(03)00024-0

Jano-Ito, M.A., Crawford-Brown, D., 2017. Investment decisions considering economic, environmental and social factors: An actors' perspective for the electricity sector of Mexico. Energy 121, 92-106. https://doi.org/10.1016/j.energy.2017.01.016

JGCRI, 2017. Global Change Assessment Model | Joint Global Change Research Institute [WWW Document], URL http://www.globalchange.umd.edu/gcam/ (accessed 11.10.17).

Joint Research Centre, 2013. The JRC-EU-TIMES model Assessing the long-term role of the SET Plan Energy technologies. doi: 10.2790/97596

Keshavarz, E., Toloo, M., 2015. Efficiency status of a feasible solution in the Multi-Objective Integer Linear Programming problems: A DEA methodology. Appl. Math. Model. 39, 3236-3247. https://doi.org/10.1016/j.apm.2014.11.032

Krey, V., 2014. Global energy-climate scenarios and models: a review. Wiley Interdiscip. Rev. Energy Environ. 3, 363-383. https://doi.org/10.1002/wene.98

Lahtinen, T.J., Hämäläinen, R.P., Liesiö, J., 2017. Portfolio decision analysis methods in environmental decision making. Environ. Model. Softw. 94, 73-86. https://doi.org/10.1016/j.envsoft.2017.04.001

Lempert, R.J., Warren, D., Henry, R., Button, R.W., Klenk, J., Giglio, K., 2016. Defense Resource Planning Under Uncertainty: An Application of Robust Decision Making to Munitions Mix Planning. $\begin{array}{llll}\text { Santa } & \text { Monica, } & \text { CA: } & \text { RAND }\end{array}$ https://www.rand.org/pubs/research_reports/RR1112.html. (accessed 11.24.17).

Mavrotas, G., 2009. Effective implementation of the $\varepsilon$-constraint method in Multi-Objective Mathematical Programming problems. Appl. Math. Comput. 213, 455-465. https://doi.org/10.1016/j.amc.2009.03.037

Mavrotas, G., Florios, K., 2013. An improved version of the augmented $\varepsilon$-constraint method (AUGMECON2) for finding the exact pareto set in multi-objective integer programming problems. Appl. Math. Comput. 219, 9652-9669. https://doi.org/10.1016/j.amc.2013.03.002

Mavrotas, G., Pechak, O., 2013. Combining Mathematical Programming and Monte Carlo Simulation to Deal with Uncertainty in Energy Project Portfolio Selection, in: Assessment and Simulation Tools for Sustainable Energy Systems, Green Energy and Technology. Springer, London, pp. 333-356. https://doi.org/10.1007/978-1-4471-5143-2_16

Mazidi, M., Monsef, H., Siano, P., 2016. Design of a risk-averse decision making tool for smart distribution network operators under severe uncertainties: An IGDT-inspired augment $\varepsilon$-constraint based multi-objective approach. Energy 116, 214-235. https://doi.org/10.1016/j.energy.2016.09.124

Monfreda, C., Ramankutty, N., Hertel, T., 2008. Global Agricultural Land Use Data for Climate Change Analysis (GTAP Working Paper). Center for Global Trade Analysis, Department of Agricultural Economics, Purdue University.

Muratori, M., Ledna, C., McJeon, H., Kyle, P., Patel, P., Kim, S.H., Wise, M., Kheshgi, H.S., Clarke, L.E., Edmonds, J., 2017. Cost of power or power of cost: A U.S. modeling perspective. Renew. Sustain. Energy Rev. 77, 861-874. https://doi.org/10.1016/j.rser.2017.04.055

[Type here] 
This document is the Accepted Manuscript version of a Published Work that appeared in final form in:

Forouli A., Doukas H., Nikas A., Sampedro J., Van de Ven D.-J. 2019. Identifying optimal technological portfolios for European power generation towards climate change mitigation: A robust portfolio analysis approach. Utilities Policy. 57. 33-42. DOI (10.1016/j.jup.2019.01.006).

(C) 2019 Elsevier Ltd. All rights reserved.

This manuscript version is made available under the CC-BY-NC-ND 3.0 license http://creativecommons.org/licenses/by-nc-nd/3.0/

Nikas, A., Doukas, H., \& Papandreou, A. (2018, in press). A Detailed Overview and Consistent Classification of Climate-Economy Models. In Understanding Risks and Uncertainties in Energy and Climate Policy: Multidisciplinary Methods and Tools towards a Low Carbon Society. Springer, Berlin, Germany.

Nikas, A., Doukas, H., Lieu, J., Alvarez Tinoco, R., Charisopoulos, V., \& van der Gaast, W. (2017). Managing stakeholder knowledge for the evaluation of innovation systems in the face of climate change. Journal of Knowledge Management, 21(5), 1013-1034.

On a Bicriterion Formulation of the Problems of Integrated System Identification and System Optimization, 1971. . IEEE Trans. Syst. Man Cybern. SMC-1, 296-297. https://doi.org/10.1109/TSMC.1971.4308298

Pachauri, R.K., Meyer, L., Plattner, G.-K., Stocker, T., 2015. IPCC, 2014: Climate Change 2014: Synthesis Report. Contribution of Working Groups I, II and III to the Fifth Assessment Report of the Intergovernmental Panel on Climate Change. IPCC.

Peniwati, K., 2007. Criteria for evaluating group decision-making methods. Math. Comput. Model., Decision Making with the Analytic Hierarchy Process and the Analytic Network Process 46, 935947. https://doi.org/10.1016/j.mcm.2007.03.005

Pérez Odeh, R., Watts, D., Negrete-Pincetic, M., 2018. Portfolio applications in electricity markets review: Private investor and manager perspective trends. Renew. Sustain. Energy Rev. 81, 192-204. https://doi.org/10.1016/j.rser.2017.07.031

Pietzcker, R.C., Ueckerdt, F., Carrara, S., de Boer, H.S., Després, J., Fujimori, S., Johnson, N., Kitous, A., Scholz, Y., Sullivan, P., Luderer, G., 2017. System integration of wind and solar power in integrated assessment models: A cross-model evaluation of new approaches. Energy Econ. 64, 583599. https://doi.org/10.1016/j.eneco.2016.11.018

Pugh, G., Clarke, L., Marlay, R., Kyle, P., Wise, M., McJeon, H., Chan, G., 2011. Energy R\&D portfolio analysis based on climate change mitigation. Energy Econ., Special Issue on The Economics of Technologies to Combat Global Warming 33, 634-643. https://doi.org/10.1016/j.eneco.2010.11.007

Rayat, F., Musavi, M., Bozorgi-Amiri, A., 2017. Bi-objective reliable location-inventory-routing problem with partial backordering under disruption risks: A modified AMOSA approach. Appl. Soft Comput. 59, 622-643. https://doi.org/10.1016/j.asoc.2017.06.036

Scott, M. J., Sands, R. D., Edmonds, J., Liebetrau, A. M., Engel, D. W., 1999. Uncertainty in integrated assessment models: modeling with MiniCAM 1.0. Energy Policy. 27, 855-879. https://doi.org/10.1016/S0301-4215(99)00057-9

Shi, W., Ou, Y., Smith, S.J., Ledna, C.M., Nolte, C.G., Loughlin, D.H., 2017. Projecting state-level air pollutant emissions using an integrated assessment model: GCAM-USA. Appl. Energy 208, 511521. https://doi.org/10.1016/j.apenergy.2017.09.122

Turnheim, B., Berkhout, F., Geels, F., Hof, A., McMeekin, A., Nykvist, B., \& van Vuuren, D. (2015). Evaluating sustainability transitions pathways: Bridging analytical approaches to address governance challenges. Global Environmental Change, 35, 239-253.

Urban, F. R. M. J., Benders, R. M. J., Moll, H. C., 2007. Modelling energy systems for developing countries. Energy Policy. 35, 3473-3482. https://doi.org/10.1016/j.enpol.2006.12.025

Uusitalo, L., Lehikoinen, A., Helle, I., Myrberg, K., 2015. An overview of methods to evaluate uncertainty of deterministic models in decision support. Environ. Model. Softw. 63, 24-31. https://doi.org/10.1016/j.envsoft.2014.09.017

[Type here] 
This document is the Accepted Manuscript version of a Published Work that appeared in final form in:

Forouli A., Doukas H., Nikas A., Sampedro J., Van de Ven D.-J. 2019. Identifying optimal technological portfolios for European power generation towards climate change mitigation: A robust portfolio analysis approach. Utilities Policy. 57. 33-42. DOI (10.1016/j.jup.2019.01.006).

(c) 2019 Elsevier Ltd. All rights reserved.

This manuscript version is made available under the CC-BY-NC-ND 3.0 license http://creativecommons.org/licenses/by-nc-nd/3.0/

Valentine, S.V., 2011. Emerging symbiosis: Renewable energy and energy security. Renew. Sustain. Energy Rev. 15, 4572-4578. https://doi.org/10.1016/j.rser.2011.07.095

van Vliet, M., Kok, K., Veldkamp, T., 2010. Linking stakeholders and modellers in scenario studies: The use of Fuzzy Cognitive Maps as a communication and learning tool. Futures 42, 1-14. https://doi.org/10.1016/j.futures.2009.08.005

Vuuren, D.P. van, Edmonds, J., Kainuma, M., Riahi, K., Thomson, A., Hibbard, K., Hurtt, G.C., Kram, T., Krey, V., Lamarque, J.-F., Masui, T., Meinshausen, M., Nakicenovic, N., Smith, S.J., Rose, S.K., 2011. The representative concentration pathways: an overview. Clim. Change 109, 5. https://doi.org/10.1007/s10584-011-0148-z

Weyant, J., 2017. Some Contributions of Integrated Assessment Models of Global Climate Change. Rev. Environ. Econ. Policy 11, 115-137. https://doi.org/10.1093/reep/rew018

Xidonas, P., Doukas, H., Mavrotas, G., Pechak, O., 2016a. Environmental corporate responsibility for investments evaluation: an alternative multi-objective programming model. Ann. Oper. Res. 247, 395-413. https://doi.org/10.1007/s10479-015-1820-x

Xidonas, P., Hassapis, C., Mavrotas, G., Staikouras, C., Zopounidis, C., 2016b. Multiobjective portfolio optimization: bridging mathematical theory with asset management practice. Ann. Oper. Res. 1-22. https://doi.org/10.1007/s10479-016-2346-6

[Type here] 